\title{
TELOMERE BIOLOGY: TELOMERE STRUCTURE, FUNCTION AND RELATED DISEASES
}

\author{
Ranjan Kumar ${ }^{1}$

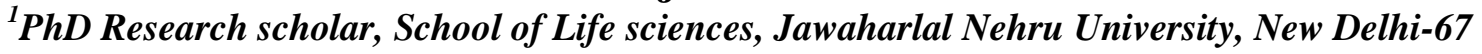

\author{
Deepika Bhardwaj ${ }^{2}$ \\ 2. PhD Research scholar, South Asian University, New Delhi-21
}

\author{
Shikha Bharati ${ }^{3}$ \\ ${ }^{3}$ PhD Research scholar, School of Life sciences, Jawaharlal Nehru University, New Delhi-67 \\ Manoj Kumar ${ }^{4}$ \\ 4. PhD Research scholar, School of Life sciences, Jawaharlal Nehru University, New Delhi-67
}

\begin{abstract}
Telomere is the special heterochromatin structure which caps the end of eukaryotic chromosome and ensures the faithful replication of genetic materials. It also provides the protection against $D N A$ damage signals and ensures the genome integrity and stability. Telomerase complete its task by its unique nucleoprotein structure. Here in this paper detail about nucleoprotein structure and their function is included. Robustness of function of telomere across cell cycle is guaranteed by the interaction between telomere and its interacting proteins. Recent findings regarding telomere biology and cancer are also included in this paper.
\end{abstract}

KEY WORDS: Telomere, $D N A$ damage, cell cycle, cancer

\section{INTRODUCTION}

Concept of telomere came in the existence before the elucidation of DNA double helix after Herman Muller and Barbara Mc Clintock findings. Muller used X-rays to fragment the chromosome and gave functional description of telomere. Both Herman Muller and Barbara McClintock working with fruit flies, and maize respectively made the same conclusion concurrently regarding natural end of chromosome. They concluded that natural end of chromosome is different from chromosomal break end. In 1938 term 'telomere' came in existence when Muller named the natural end of chromosome 'telomeres' (Muller, 1938). The word telomere came from combination of two Greek words telos and meros, meaning end and part respectively.

Nobel prize in physiology and medicine in 1946 and 1983 were awarded to Muller and Barbara McClintock respectively. At that time due to lack of appropriate tools the molecular nature of telomere was unknown. Watson and Crick double helical structure of DNA reported in 1953 (Watson and Crick, 1953), suggests mechanism for its replication. In 1960s Arthur Kornberg discovered DNA polymerase which is responsible for DNA replication. After the discovery of DNA polymerase end replication problem in case of linear DNA came in light due to the inherent property of DNA polymerase's inability to replicate linear DNA to 


\section{EPRA International Journal of Research and Development (IJRD)

completion (Kornberg, 1974). In 1975 Elizabeth Blackburn joined the laboratory of Joseph Gall at Yale after completing her Ph.D from Frederick sangers laboratory. She wanted to apply her knowledge of DNA sequencing to understand the molecular nature of chromosome termini. On sequencing the native ends of macromolecular ribosomal DNA of Tetrahymena, Blackburn found that they consist of non-coding 5'-TTGGGG-3' variable repeats which varies from molecule to molecule. Elizabeth Blackburn and Jack Szostak together performed experiment by adding DNA end of linear DNA from ribosomal DNA of Tetrahymena to artificial chromosome in yeast which protect it from degradation (Blackburn and Szostak, 1984). Blackburn with her graduate student Carol Greider discovered telomerase. In 2009 Elizabeth H. Blackburn along with Carol W Greider and Jack W Szostak were awarded Nobel prize in Physiology or Medicine for their work on protection of chromosomes by telomeres and the enzyme telomerase.

In this paper telomere, structure, function and its related diseases are discussed in detail. Telomere is a heterochromatin structure made up of telomeric DNA and proteins associated with telomere present at the end of chromosome. Its main function is maintaining the integrity of chromosome from preventing them from being recognized from ds DNA break repair system. The length of telomere is maintained by recruiting telomerase at the telomeric DNA. IT has TERT subunit which act as reverse transcriptase and has TERC subunit which acts as template for addition of telomere. Telomerase has many non-telomeric function also like RNA dependent RNA polymerase activity, regulation of gene expression, regulation of apoptosis and role in DNA repair. The protein complexes mainly shelterin interacting telomeric DNA provides stability to the chromosome, helps in recruitment of telomerase and regulates length of telomere. Telomere length is regulated by telomerase, components of shelterin complexes and epigenetic regulation. Any defects in telomere regulators causes telomere related diseases.

\section{TELOMERE}

Special heterochromatin structure capping the ends of eukaryotic chromosome helps in maintaining the structural integrity and ensures complete replication of the ends of eukaryotic chromosome. These caps prevent the loss of genetic material and prevent the recognition of DNA double strand break of chromosome by signalling mechanism associated with DNA damage (Karlseder et al. ,2001; Artandi, 2006). It hinders the fusion of the chromosome end with neighbouring chromosomes (end to end fusion) and degradation which lead to cellular senescence or even apoptosis. Telomeres arrange to form loop structure (T-loop and D-loop) which act as protective chromosomal cap.

\section{MOLECULAR STRUCTURE OF TELOMERE}

Telomeres are generally composed of DNA and multiple DNA binding proteins (Greider et. al., 1996; Wellinger and McElligott, 1997).

Telomeric DNA in mammals consists of TTAGGG in 5' - $3^{\prime}$ and its complementary $3^{\prime}$ AATCC $5^{\prime}$ sequences followed by $3^{\prime} \mathrm{G}$-rich single-stranded overhangs of 30-500 nucleotides long. This singlestranded 3 'G-rich overhang is the telomeric end key feature in all organisms (Makarov et. al., 1997; Wellinger and McElligott, 1997). 5'C-rich singlestranded overhang is reported to be found in worms (Raices et. al., 2008) and also occurs in certain cancer cells transiently (Karlseder and Oganesian, 2011).

Telomeres shorten at each cell division and ultimately lead to critically short non-functional telomeres which further leads to replicative senescence (telomere dependent cell cycle arrest). This shortening happens due to the inability of the replication machinery (DNA polymerase) to replicate linear DNA to completion. Telomere length can be maintained by two mode- (1) Telomere dependent, (2) recombination based system (Alternative Lengthening of Telomeres, ALT). But in dipterans telomere lengths are maintained by retrotransposons insertion to the chromosome ends (Mason and Biessmann, 1995; Mason et al., 2008).

\section{TELOMEREASE}

The telomerase is a unique ribonucleoprotien complex which resolves the problem of end replication by extending the ends of newly replicated chromosomes with telomeric repeats through its reverse transcriptase activity. Human telomerase consists of at least six subunits: - 1) human telomerase RNA component or hTERC; 2) human telomerase reverse transcriptase or hTERT; 3) heat shock protein 90 or hsp90;4) telomerase associated protein or TEP1; 5) p23; 6) dyskerin. Among these six subunits, the core subunits are hTERC and hTERT. Rate limiting component of telomerase is hTERT as its expression level changes proportionately during up and down regulation of telomerase and rest of the components remains unchanged (Chang,J.T. et al.,2002).

\subsection{TELOMERASE RNA COMPONENT (TERC)}

TERC is the RNA constituent of the telomerase holo-enzyme which is the template for telomeric DNA extension (Blackburn, E.H. and Greider, C.W., 1989). It is one among all those factors which influences the processivity of 


\section{EPRA International Journal of Research and Development (IJRD)

telomerase. Human TERC gene is located on chromosome 3 and its locus is $3 \mathrm{q} 26.3$ (Feng, J. et al.,1995). Size of TERC varies among species. Size hTERC is 451 nucleotides (Blasco, M.A. et al.,1995). Telomerase RNA shows less conservance during evolution. It shows that between species, the primary sequence is diverse but secondary structure is remarkably conserved which indicates the importance of RNA structure in telomerase activity (Chen, J.L. et al. ,2000).

$3^{\prime}$ end of the hTERC contains sequence motif of H/ACA and form a non-coding RNA specific class which facilitates the modification of other cellular RNA (Mitchell et. al.,1999, Chen et. al., 2000). These H/ACA RNA are divide into two groups on the basis of localization (nucleolus and cajal bodies)- i) H/ACA small nucleolar RNA (snoRNA) accumulated in nucleolus, it participates in modification of ribosomal RNA (Mitchell et al. ,2000). ii) Cajal body specific RNA (scaRNA) accumulated in Cajal bodies, it participates in the modification of splicing RNA (Matera et al. ,2007). $\mathrm{CAB}$ or Cajal body box is another sequence motif responsible for different localization of snoRNA and scaRNA in the cell.

The accumulation, maturation and stability of hTERC depends on interactions of hTERC conserved domain with hTERC-binding proteins (La, hnRNP, dyskerin, hTERT etc.). These interactions of RNAprotein are found to be involved in telomerase assembly in a functional form (Dragon et al., 2000; Pogacic et al.,2000).

\subsection{TELOMERASE REVERSE TRANSCRIPTASE (TERT)}

TERT is the telomerase's core subunit and have RNA dependent DNA polymerase activity which synthesizes DNA by using its own RNA template. The location of gene encoding human TERT is found to be on chromosome 5 (5p15.33). hTERT gene stretchess more than $37 \mathrm{~kb}$, containing 16 exons and 15 introns coding 1132 amino acid residues (Wick et al.,1999). In humans (hTERT), protozoans, Saccharomyces cerevisiae (Est2), and Schizosaccharomyces pombe (Trt1), this subunit is found to be conserved (Lingner et al.,1997, Nakamura et al.,1997). TERT protein has 4 domains - RNA binding domain (TRBD), palm, finger and thumb (Gillis et al.,2008).

On the basis of structure and function, TERT protein can be classified into three main domains the thumb, palm and finger subdomains containing reverse transcriptase domain, telomerase essential Nterminal domain and TERT RNA binding domain. These TERT subunits show conservation with reverse transcriptase or retroviruses. Tert expression level varies in normal and immortal cells. Low or undetectable expressions is often found in somatic cells (normal cells) while immortal cells show high expression (M.A. Blasco, 2005). The over-expression of TERT has been found to increase lifespan of mice by over-expressing tumor suppressor genes such as p16, p19 and p53 (Zhang et al.,2010). Oncogenes, tumor suppressor genes (TSG) and surrounding chromatin regulates TERT transcription. According to Liu and colleagues, interactions of C-terminus of p53 and human telomerase associated protein 1 (hTEP1) causes inhibition of activity of telomerase (Li et al.,1999).

\subsection{TELOMERASE RECRUITMENT}

Telomerase recruitment in a timely manner to the chromosome end is the important step with for telomerase action. In Saccharomyces cerevisiae it has been found that telomerase recruitment is mediated by an interaction between ever short chromosome 1 (EST1) and Cdc13. EST1 is a constituent of telomerase complex while $\mathrm{Cdc} 13$ is a protein which binds to single-stranded overhang (Lundblad and Evans, 1999; Qiand Zakian, 2000). The Ku complex also mediates another pathway, by binding to the telomeric DNA and RNA of telomerase (Peterson et. al., 2001; Stellwagen et. al., 2003). Ku70-Ku80 complex in humans has been found in association with telomerase via interactions with both hTERT and hTERC (Chai et. al., 2002; Ting et. al., 2005). The role of $\mathrm{Ku}$ in recruitment mechanism of telomerase to telomere in mammals is still not clear. $\mathrm{Ku} 70$ - deficient mouse is found to show no defect in telomere maintenance (Celli et al., 2006). TERT and TPP1 interaction enhances the processivity of telomerase (Wang et al., 2007; Xin et al.,2007) and this interaction is required for the repression of the DNA damage response. Several studies have found the role of TPP1 in telomerase recruitment (Abreu et al., 2010) and the bridging of telomerase to telomere through hetrogenous nuclear RNP protein A1(LaBranche et al., 1998).

\section{TELOMERE BINDING PROTEINS - TELOMERE MAINTENANCE AND CHROMOSOME STABILITY}

Telomeric DNA interacts with a set of specialized proteins which comprises of different constituents, layouts and roles beyond species (de Lange, 2009). Telomere maintenance in mammalian cells depend on the interaction of six protein complexes at the telomere. These six protein complexes are termed as telosome or shelterin complexes (D.Liu et al.,2004,T.deLange et al.,2005). Components of shelterin complexes are: TRF1, TRF2, TIN2, RAP1, POT1, TPP1 (T.deLange et al.,2005). Shelterin complex plays a major role in chromosome stability by distinguishing chromosome ends to protect it from DNA damage and repair pathways (namely NHEJ, ATR, ATM, NHEJ, HDR and resection). 


\section{EPRA International Journal of Research and Development (IJRD)

\subsection{TRF1}

TRF1 binds as homodimers to the duplex region of telomeric DNA and acts as negative regulator of telomere length (B. van Steensel et al.,1997). Dimerization occurs through TRF homology (TRFH) domain which also mediates the interactions with other telomeric proteins. TRF1 has a distinct protective function. It overcomes the major challenges of DNA replication machinery regarding the G-rich and highly repetitive nature of telomeric DNA. It protects the telomeric end from breakage when copying of telomeric DNA takes place by promoting the DNA replication machinery (Martı'nez et al., 2009; Sfeir et al.,2009). In mice, homozygous inactivation of TRF1 is embryonic lethal and cannot be rescued even in absence of telomerase, showing important role of TRF1 which doesn't act according to the length of telomere (J.Karlseder et al.,2003).

\subsection{TRF2}

TRF2 binds to double stranded telomeric DNA, playing a pivotal role in maintenance of telomere by negative regulation and protecting its end. TRF2 recruits various factors for telomere regulation. Homozygous deletion of TRF2 in mice, like TRF1, is embryonic lethal. Activation of kinase ATM takes place by TRF2 deletion (Celli and de Lange,2005), which leads to the assembly of DNA damage factors like 53BP1,H2AX at the telomere (Dimitrova and de Lange, 2006; Denchi and de Lange, 2007; Dimitrova and de Lan ge, 2009). Activation of p53 is done by ATM by phosphorylating it. After activation p53 acts as transcription factor for $\mathrm{p} 21$ gene and leads to synthesis of $\mathrm{p} 21$ protein which acts as cyclin inhibitor and induces cell cycle arrest. TRF2 absence also activates ligase 4 and $\mathrm{Ku}$ mediated NHEJ repair at telomeres, resulting in end to end fusions of chromosome (Celli and Lange,2005). The mechanism of the repression of NHEJ and ATM is not known and is currently under investigation. The repression may be due to covering of telomere terminus in the t-loop structure formed by TRF2. This is derived by the observation that in-vitro purified TRF2 binds at the junction of t-loop (Stansel et al.,2009), promoting the formation of structure resembling t-loop (Poulet et al.,2009). A t-loop structure prevents the detection of telomere end by DNA damage sensor of the ATM pathway. This structure also blocks NHEJ repair by preventing binding of $\mathrm{Ku} 70-\mathrm{Ku} 80$ complex to telomere terminus.

\subsection{POT1}

POT1 is a single stranded, G-rich DNA binding protein. It coats the telomeric overhang with its oligonucleotide / oligosaccharide binding (OB) folds. N-terminal OB fold binds to the six nucleotides and second $\mathrm{OB}$ fold binds and protects $3^{\prime}$ end of single stranded DNA (M. Lei et al.,2004). Mice have two paralogs of POT1 (POT1a and POT1b) with similar structure and distinct function (Hockemeyer et al.,2006). POT1 and POT1a in humans and mice respectively, repress the ATR mediated DNA damage response. The length of the single stranded overhang is regulated by POT1b (Hockemeyer et al.,2005; Hockemeyer et al., 2006; Wu et al.,2006). POT1 and POT1a blocks the ATR pathway by preventing the binding / excluding the replication protein A (RPA) to single stranded telomeric DNA. RPA is a single stranded binding protein and sensor in the ATR pathway. From recent studies it has been demonstrated that hnRNPA1, TERRA and POT1 act together to displace RPA from telomeric single stranded DNA after DNA replication, promoting telomere end protection (R.L. Flynn et al.,2011).

TERRA (telomeric repeat containing RNA) is a non-coding RNA and is found to be important in telomere maintenance and function (Redon et al., 2010; Flynn et al., 2011). Transcription of this noncoding RNA is done by RNA polymerase II and the initiation is from the sub-telomeric regions (Porro et al., 2010). TERRA is one of the components of the telomere nucleoprotein complex (Azzalin et al., 2007).

\subsection{RAP1}

Mammalian RAP1 interacts with TRF2 for telomere localization as they lack telomere binding capacity ( $\mathrm{Li}$ et al.,2000). RAP1 inhibits homology directed repair (HDR) at telomeres. RAP1, POT1 and $\mathrm{Ku}$ are found to cooperate to block recombination, however the mechanism has not yet been elucidated.

\subsection{TPP1}

Large scale affinity purification is used for the purification of this protein. TPP1 is found to interact both with TIN2 and POT1 (Liu te al.,2004). TPP1 helps in the recruitment of POT1 and telomerase at telomere (Wang et al.,2007; Xin et al.,2007). TPP1 also shows interaction with ss-telomeric DNA binding protein $\mathrm{OBFC} 1 / \mathrm{Stn} 1$, which controls the telomere length by negative regulation $(\mathrm{Wu}$ et al.,2012). Hence TPP1 protects telomere end via repression of ATR mediated DNA damage signalling and regulates telomere length by recruiting telomerase at telomere.

\subsection{TIN2}

TIN2 is the central component of shelterin complex as it directly interacts with TRF1, TRF2 and TPP1. It helps in telomere localization of all telomeric components (O’Connor et al., 2006). In mice TIN2 inactivation is embryonic lethal as it facilitates the TRF2-dependent inhibition of ATM mediated DNA repair, telomerase recruitment and control of telomere length (Takai et al., 2011). 


\section{EPRA International Journal of Research and Development (IJRD)

\subsection{Other Functions of telomere Proteins}

Telomerase and telomere proteins have wide range of functions rather than telomere length regulation and telomere end stability. Some telomere proteins localize and interact in the cytoplasm, such as TIN2, TPP1, and POT1 (Chen et al., 2007). TRF2 play an important role in regulation of stem cells and neural tumor proliferation and differentiation (Zhang et al., 2008; Zhang et al., 2006). It is also involved in the homologous recombination (HR) repair of DSB at the non-telomeric regions (Mao et al., 2007; Bradshaw et al., 2005). TIN 2 possess mitochondrial localization signal. Recently it has been found that TIN2 has some role in metabolic control as RNAi mediated silencing of TIN2 enhances oxygen consumption and mitochondrial ATP synthesis (Chen et al., 2012). Telomerase has also non-telomeric function. Telomerase can regulate apoptotic responses due to oxidative stress by localizing to the mitochondria and sensitizing the mitochondrial DNA to hydrogen peroxide. Protein subunit of telomerase, TERT, has a N-terminal leader sequence containing mitochondrial localization signal that target TERT to mitochondria (Haendeler et al., 2003). Mitochondrial oxidative stress triggers the TERT nuclear export (Haendeler te al., 2004). Telomerase show RNA dependent RNA-polymerase activity in mitochondria, act as transcription factors in Wnt signalling pathway and are also involved in regulation of DNA repair and apoptosis.

\section{TELOMERE RELATED HUMAN DISEASES}

Somatic cells are prone to telomere shrinkage as they lack telomerase. Shortening of telomere may loosen the protective shelterin complex binding, forcing the cell to face two outcomes. Telomere eroded cells undergoes the process of cell senescence with checkpoints but telomere dysfunction in p53 lacking cells causes genomic instability and further lead to tumor progression. Any defect in telomere regulators contribute to human diseases which are of various origins and associated with ageing like heart disease, liver cirrhosis, ulcerative colitis and atherosclerosis (Wiemann et al., 2002; Samani et al., 2001). Short telomere length can directly contribute to premature ageing syndromes like Dyskeratosis congenital, Aplastic anaemia, Wrener syndrome, Bloom syndrome, ATM syndrome.

Telomere dysfunction also leads cancer formation in cells lacking cell cycle check points. Telomerase activity is absent in normal human cells and thus they face the problem of telomere shortening with each cell cycle and when they reach up to the critical length they undergo the process of replicative senescence. But cells lacking cell cycle check points continue to divide by evading replicative senescence. They further face the growths arrest state i.e. crisis. In absence of telomerase and telomeric proteins many small chromosome ends fuses and ultimately lead to apoptosis. Cells escaping crisis show two important hallmarks i.e. telomere stability and re-activation of expression of telomerase. Thus, these cells grow continuously, resulting in carcinogenesis. Short telomeres are recognized as double strand breaks and induces the non- homologous end joining pathway based DNA damage repair which results in end-to-end chromosomal fusions. When these fused chromosomes undergo the mitotic cycles results in breakage of fused chromosomes and finally chromosomal aberrations. This accumulation of chromosomal aberrations leads to malignant transformation (Blasco et al., 1997). Approximately in $90 \%$ of the all malignant tumors have high expression of telomerase (Kim et al., 1994; Blasco and Hahn, 2003). In many types of cancer there is amplification of $5 \mathrm{p} 15.33$ loci which codes for telomerase subunit TERT (Hahn and Meyerson, 2001).

\section{THERAPEUTIC APPROACHES}

Diseases caused by human ageing and syndromes of premature ageing due to short telomere can be corrected by temporary telomerase reactivation. The germ-line introduction of telomerase leads to extension of telomere length in mouse models of inherited short telomere. This prevented the end-toend fusion of chromosomes which solves the problems related to disease linked with chromosome fusion like bone marrow aplasia, infertility, hypogonadism and intestinal epithelium atrophy (Samper et al., 2001). Reintroduction of telomerase TERT subunit with NBS1 in cultured cells can correct the Nijimegen breakage syndrome (Ranganathan et al., 2001). Werner syndrome cells having short telomeres can be corrected by reintroduction of telomerase which extends the lifespan of the cells (Wyllie et al., 2000). But there is problem with reintroduction of telomerase in telomerase deficient cells that it may grow continuously and lead to tumor formation.

\subsection{Therapeutical Approach Regarding Cancer}

In $80-90 \%$ of cancers, there is elevation in expression level of telomerase. Telomerase inhibition thus can be an effective strategy to control tumor growth (Shay et al., 2002). Therapeutic strategies that focus on telomerase targeting in cancer cells have been designed in the past recent years. Targeted inhibition of telomerase in tumor triggers the shortening of chromosome which lead to loss of cell viability in tumor.

Use of small synthetic molecules to inhibit the telomerase enzymatic activity is becoming popular. 


\section{EPRA International Journal of Research and Development (IJRD)

2-[[E]-3-naphthalene-2-yl-but-2-enoylamino]-

benzoic acid or BIBR1532 is a non-competitive inhibitor of both TERT and TERC (Pascolo et al., 2002). Treatment of cells with this drug, in-vitro, gave positive result regarding telomere length reduction and inhibition of cell proliferation. But it is cytotoxic at higher dose (Damm et al., 2001). Gquadruplex stabilization inhibits telomerase activity by preventing TERC telomerase subunit from recognizing 3' overhang hydroxyl group on single stranded telomeric DNA. Small synthetic molecules such as G-quadruplex ligands, have been used for the stabilization of quadruplex structure of telomere (Neidle, 2010). Telomestatin macrocyclic compound from Streptomyces anulatus used as G-quadruplex ligands and potentially inhibits telomerase (Kim et al., 2001). To overcome the problems regarding small molecule inhibition immunotherapy in which tumor associated antigen (TAAs), TERT-based vaccination etc. and gene therapy involving TERT or TERC expression inhibition by siRNA, utilization of promoters of TERT or TERC for exogenous vectors expression etc. are used.

\subsection{Challenges}

Telomerase expression is observed in blood cells in bone marrow, skin basal layer cells, and epithelial cells of the mucosa. Thus different therapeutic approach targeting telomerase can affect the normal cells. Generally, tumor cells have shorter telomeres than the surrounding normal tissues as tumor cells proliferation rates are high which causes decrease in their telomere length. Some more challenges regarding therapeutic potentials are issue of short telomere, ideal target, pharmaco-kinetic, and safety issues.

The combination of already established therapies of cancer and treatments based on telomerase may be effective strategy to overcome these challenges.

\section{CONCLUSION AND FUTURE PERSPECTIVES}

From the above gathered information it is clear that telomere shortening with increasing age or mutations are the main cause of human diseases.

Telomere a special heterochromatin caps the end of chromosome and provides stability. Telomere length is maintained by telomerase, different telomere interacting proteins and epigenetic regulation. They key step in telomere length maintenance is recruitment of telomerase on telomere which is controlled by many factors. Any defect in the telomere maintenance machinery leads to human age related diseases, premature ageing syndromes and cancers. Telomerase extra telomeric functions have also been confirmed which promotes tumorigenesis. There are still more to explore in this field. By having depth study at molecular level of epigenetic regulation, telomerase and telomere binding protein and their interaction with other proteins or molecules can explore many things about them and their regulations in cell which may help in correcting telomeric defects. In case of cancer due to lack of depth therapeutic strategies fails in in vivo experiments. Deep knowledge about telomere biology and specific targeting may solve the challenges regarding therapeutic approaches in telomere related diseases.

\section{REFERENCES}

1. Abreu E, Aritonovska E, Reichenbach $P$, Cristofar G, Culp B, Terns RM, Lingner $J$ and Terns MP (2010): TIN2-tethered TPP1 recruits human telomerase to telomeres in vivo. Mol Cell Biol. 30, 2971- 2982.

2. Azzalin $C M$, Reichenbach $P$, Khoriauli $L$, Giulotto E and Lingner J (2007): Telomeric repeat containing RNA and RNA surveillance factors at mammalian chromosome ends. Science. 318, 798-801.

3. $B$ Li, $S$ Oestreich, $T$ de Lange (2000): Identification of human Rap1: implications for telomere evolution. Cell. 101, 471-483.

4. B.vanSteensel, $T$ de Lange (1997): Control of telomere length by the human telomeric protein TRF1. Nature. 385,740-743.

5. Blackburn EH \& Szostak JW (1984): The molecular structure of centromeres and telomeres. Annu Rev Biochem. 53, 163-194.

6. Blasco MA and Hahn WC (2003): Evolving views of telomerase and cancer. Trends Cell Biol. 13, 289-294.

7. Blasco MA, Funk W, Villeponteau B and Greider CW (1995): Functional characterization and developmental regulation of mouse telomerase RNA. Science. 269, 1267-1270.

8. Blasco MA, Lee HW, Hande MP, Samper E, Lansdorp PM, DePinho RA \& Greider CW (1997): Telomere shortening and tumor formation by mouse cells lacking telomerase RNA. Cell. 91, 25-34.

9. Celli $G$ B, Denchi $E L$ and de Lange $T$ (2006): $\mathrm{Ku} 70$ stimulates fusion of dysfunctional telomeres yet protects chromosome ends from homologous recombination. Nat Cell Biol. 8, 855-890.

10. Celli $G B$ and de Lange $T$ (2005): DNA processing is not required for ATM-mediated telomere damage response after TRF2 deletion. Nat Cell Biol. 7, 712-718.

11. Chai W, Ford LP, Lenertz L, Wright W E and Shay JW (2002): Human Ku70/80 associates physically with telomerase through interaction with hTERT. J Biol Chem. 277, 47242-47247.

12. Chang JT, Chen YL, Yang HT, Chen $C Y$ and Cheng AJ (2002): Differential regulation of telomerase activity by six telomerase subunits. Eur. J. Biochem. 269, 3442-3450. 


\section{EPRA International Journal of Research and Development (IJRD)}

13. Chen JL, Blasco MA and Greider CW (2000): Secondary structure of vertebrate telomerase RNA. Cell. 100, 503-514.

14. D Hockemeyer, JP Daniels, H Takai, T de Lange (2006): Recent expansion of the telomeric complex in rodents: two distinct POT1 proteins protect mouse telomeres, Cell. 126, 63-77.

15. D Liu, A Safari, MS O'Connor, DW Chan, A Laegeler, J Qin, Z Songyang (2004): PTOP interacts with POT1 and regulates its localization to telomeres, Nat Cell Biol. 6, 673680.

16. D Liu, MSO'Connor J. Qin Z Songyang (2004): Telosome, a mammalian telomere-associated complex formed by multipletelo meric proteins, JBiolChem. 279, 51338-51342.

17. Damm K et al. (2001): A highly selective telomerase inhibitor limiting human cancer cell proliferation. EMBO J. 20, 6958-6968.

18. de Lange $T$ (2009): How telomeres solve the endprotection problem. Science. 326, 948-952.

19. Denchi E L and de Lange T (2007): Protection of telomeres through independent control of ATM and ATR by TRF 2 and POT1. Nature. 448, 10681071.

20. Dimitrova $N$ and de Lange $T$ (2006): $M D C 1$ accelerates nonhomologous end-joining of dysfunctional telomeres. Genes Dev. 20, 32383243.

21. Dimitrova $N$ and de Lange $T$ (2009): Cell cycledependent role of MRN at dysfunctional telomeres: ATM signaling-dependent induction of nonhomologous end joining (NHEJ) in G1 and resection-mediated inhibition of NHEJ in G2. Mol Cell Biol. 29, 5552-5563.

22. Dragon F, Pogacic V and Filipowicz W (2000): In vitro assembly of human H/ACA small nucleolar ribonucleoproteins reveals unique features of U17 and telomerase RNA. Mol Cell Biol. 20, 3037-3048.

23. Evans SK and Lundblad V (1999) : Est1 and Cdc13 as comediators of telomerase access. Science. 286, 117- 120.

24. F Wang, Y Yin, X Ye, K Liu, H Zhu, L Wang, $M$ Chiourea, M Okuka, GJi, J Dan, B Zuo, M Li, Q Zhang, $N$ Liu, L Chen, X Pan, S Gagos, DL Keefe, L Liu (2012): Molecular insights into the heterogeneity of telomere reprogramming in induced pluripotent stem cells. Cell Res. 22, 757768.

25. Feng J, Funk WD, Wang SS, Weinrich SL, Avilion AA, Chiu CP, Adams RR, Chang E, Allsopp RC, Yu J, Le S, West MD, Harley $C B$, Andrews WH, Greider $C W$ and Villeponteau $B$ (1995): The RNA component of human telomerase. Science. 269, 1236-1241.

26. Gillis AJ, Schuller AP and Skordalakes E (2008): Structure of the Tribolium castaneum telomerase catalytic subunit TERT. Nature. 455, 633-637.

27. Greider, CW and Blackburn EH (1989): A telomeric sequence in the RNA of Tetrahymena telomerase required for telomere repeat synthesis. Nature. 337, 331-337.
28. H Li, Y Cao, MC Berndt, JW Funder, JP Liu (1999): Molecular interactions between telomerase and the tumor suppressor protein $p 53$ in vitro. Oncogene. 18, 6785-6794.

29. H Xin, DLiu, M Wan, A Safari, H Kim, W Sun, MS O'Connor, Z Songyang (2007): TPP1 isa homologue of ciliate TEBP-beta and interacts with POT1 to recruit telomerase. Nature. 445, 559-562.

30. Haendeler J, Hoffmann J, Rahman S, Zeiher AM and Dimmeler $S$ (2003): Regulation of telomerase activity and anti-apoptotic function by proteinprotein interaction and phosphorylation. FEBS Lett. 536, 180-186.

31. Haendeler J, Hoffmann J, Diehl JF, Vasa M, Spyridopoulos I, Zeiher AM and Dimmeler $S$ (2004): Antioxidants inhibit nuclear export of telomerase reverse transcriptase and delay replicative senescence of endothelial cells. Circ Res. 94, 768-775.

32. Hahn, WC and Meyerson M (2001): Telomerase activation, cellular immortalization and cancer. Ann Med. 33, 123-129.

33. Hockemeyer D, Sfeir A J, Shay JW, Wright WE and de Lange, $T$ (2005): POT1 protects telomeres from a transient DNA damage response and determines how human chromosomes end. EMBO J. 24, 2667-2678.

34. J Karlseder, L Kachatrian, H Takai, K Mercer, S Hingorani, $T$ Jacks, $T$ de Lange (2003): Targeted deletion reveals an essential function for the telomere length regulator Trf1. Mol Cell Biol. 23, 6533-6541.

35. Kim MY et al. (2002): Telomestatin, a potent telomerase inhibitor that interacts quite specifically with the human telomeric intramolecular Gquadruplex. J Am Chem Soc. 124, 2098-2099.

36. Kim NW et al. (1994): Specific association of human telomerase activity with immortal cells and cancer. Science. 266, 2011-2015.

37. KK Takai, T Kibe, JR Donigian, D Frescas, $T$ de Lange (2011): Telomere protectionbyTPP1/POT1 requirestetheringtoTIN2 . Mol Cell. 44, 647-659.

38. Kornberg A (1974): DNA Synthesis. W.H. Freeman, San Francisco.

39. L Wu, AS Multani, $\mathrm{H}$ He W Cosme-Blanco, $Y$ Deng, JM Deng, O Bachilo, S Pathak, H Tahara, SM Bailey, RR Behringer, S Chang (2006): Pot1 deficiency initiates DNA damage checkpoint activation and aberrant homologous recombination at telo meres. Cell. 126, 49-62.

40. LaBranche H, Dupuis S, Ben-David, Y, Bani $M R$, Wellinger RJ and Chabot $B$ (1998): Telomere elongation by hnRNP Al and a derivative that interacts with telomeric repeats and telomerase. Nat Genet. 19, 199-202.

41. Lingner J, Hughes TR, Shevchenko A, Mann M, Lundblad $V$ and Cech TR (1997): Reverse transcriptase motifs in the catalytic subunit of telomerase. Science. 276, 561-567. 


\section{EPRA International Journal of Research and Development (IJRD)}

42. LY Chen, D Liu, $Z$ Songyang, Telomere maintenance through spatial control of telomeric proteins. Mol Cell Biol. 27, 5898-5909.

43. LY Chen, $Y$ Zhang, $Q$ Zhang, $H$ Li, Z Luo, $H$ Fang, SH Kim, L Qin, P Yotnda, J Xu, BP Tu, Y Bai, Z Songyang (2012): Mitochondrial localization of telomeric protein TIN2 links telomere regulation to metabolic control. Mol Cell (Epub ahead of print).

44. M Lei, ER Podell, TR Cech (2004): Structure of human POT1 bound to telomeric single-stranded DNA provides a model for chromosome end protection. Nat Struct Mol Biol. 11, 1223-1229.

45. MA Blasco (2005): Telomeres and human disease: ageing, cancer and beyond. Nat Rev Genet. 6, 611-622.

46. Makarov, $V$ L, Hirose, $Y$ and Langmore, $J P$ (1997): Long $G$ tails at both ends of human chromosomes suggest a $C$ strand degradation mechanism for telomere shortening. Cell. 88, 657-666.

47. Martınez P, Thanasoula M, Munoz P, Liao C, Tejera A, McNees C, Flores J M, FernandezCapetillo, $O$ Tarsounas $M$ and Blasco $M A$ (2009): Increased telomere fragility and fusions resulting from TRF1 deficiency lead to degenerative pathologies and increased cancer in mice. Genes Dev. 23, 2060-2075.

48. Mason JM, Frydrychova RC, and Biessmann $H$ (2008): Drosophila telomeres:anexceptionproviding new insights. Bioessays. 30, 25-37.

49. Matera AG, Terns RM and Terns MP (2007): Non-coding RNA: lessons from the small nuclear and small nucleolar RNA. Nat Rev Mol Cell Biol.8, 209-220.

50. McElligott, $R$ and Wellinger, $R J$ (1997): The terminal DNA structure of mammalian chromosomes. EMBO J. 16, 3705-3714.

51. Mitchell JR and Collins K (2000): Human telomerase activation requires two independent interactions between telomerase RNA and telomerase reverse transcriptase. Mol Cell. 6, 361-371.

52. ML Zhang, XJ Tong, XH Fu, BO Zhou, J Wang, XH Liao, QJ Li, N Shen, J Ding, JQ Zhou (2010): Yeast telomerase subunit Estlp has guanine quadruplex-promoting activity that is required for telomere elongation. Nat Struct Mol Biol. 17, 202-209.

53. MS O'Connor, A Safari, H Xin, D Liu, Z Songyang (2006): A critical role for TPP1 and TIN2 interaction in high-order telomeric complex assembly. Proc Natl Acad Sci USA. 103, 1187411879.

54. Muller HJ (1938): The remaking of chromosomes. Collecting Net. 13, 181-198.

55. Nakamura TM, Morin GB, Chapman KB, Weinrich SL, Andrews WH, Lingner J, Harley $C B$ and Cech TR (1997): Telomerase catalytic subunit homologs from fission yeast and human. Science. 277, 955-959.
56. Oganesian $L$ and Karlseder $J$ (2011): Mammalian 59 C-rich telomeric overhangs are a mark of recombinationdependent telomere maintenance. Mol Cell. 42, 224-236.

57. $P W u, \quad H$ Takai, $T$ de Lange (2012) : Telomeric30 overhangs derive from resection byExolandApolloandfill-inbyPOT1b-associated CST. Cell. 150, 39-52.

58. P Zhang, K Furukawa, PL Opresko, X Xu, VA Bohr, MP Mattson (2006): TRF2dysfunctionelicitsDNAdamageresponses associated with senescence in proliferating neural cells and differentiation of neurons. $J$ Neurochem. 97, 567-581.

59. P Zhang, MJ Pazin, CM Schwartz, KG Becker, RP Wersto, CM Dilley, MP Mattson (2008): Nontelomeric TRF2-REST interaction modulates neuronal gene silencing and fate of tumor and stem cells. Curr Biol. 18, 1489-1494.

60. Pascolo E et al. (2002): Mechanism of human telomerase inhibition by BIBR1532, a synthetic, non-nucleosidic drug candidate. J Biol Chem. 277, 15566-15572.

61. Peterson SE, Stellwagen AE, Diede SJ, Singer M $S$, Haimberger $Z W$, Johnson CO, Tzoneva $M$ and Gottschling $D E$ (2001): The function of a stemloop in telomerase RNA is linked to the DNA repair protein $\mathrm{Ku}$. Nat Genet. 27, 64-67.

62. Pogacic V, Dragon F and Filipowicz W (2000): Human H/ACA small nucleolar ribonucleoproteins and telomerase share evolutionarily conserved proteins NHP2 and NOP10. Mol Cell Biol. 20, 9028-9040.

63. Porro A, Feuerhahn $S$, Reichenbach $P$ and Lingner $J$ (2010): Molecular dissection of telomeric repeatcontaining $R N A$ biogenesis unveils the presence of distinct and multiple regulatory pathways. Mol Cell Biol. 30, 48084817.

64. Poulet A, Buisson R, Faivre-Moskalenko C, Koelblen M, Amiard S, Montel F, Cuesta-Lopez $S$, Bornet $O$, Guerlesquin $F$, Godet $T$ et al. (2009): TRF2 promotes, remodels and protects telomeric Holliday junctions. EMBO J. 28, 641 651.

65. PS Bradshaw, DJ Stavropoulos, MS Meyn (2005): Human telomeric protein TRF2 associates with genomic double-strand breaks as an early response to DNA damage. Nat Genet. 37, 193-197.

66. $Q i \quad H$, and Zakian $V$ A (2000): The Saccharomyces telomere-binding protein Cdc13p interacts with both the catalytic subunit of DNA polymerase alpha and the telomerase-associated est1 protein. Genes Dev. 14, 1777- 1788.

67. Raices $M$, Verdun R E, Compton S A, Haggblom $C$ I, Griffith $J D$, Dillin $A$ and Karlseder $J$ (2008): C. elegans telomeres contain G-strand and C-strand overhangs that are bound by distinct proteins. Cell. 132, 745-757.

68. Ranganathan $V$ et al. (2001): Rescue of a telomere length defect of Nijmegen breakage 


\section{EPRA International Journal of Research and Development (IJRD)}

syndrome cells requires NBS and telomerase catalytic subunit. Curr Biol. 11, 962-966.

69. Redon S, Reichenbach $P$ and Lingner J (2010): The non-coding RNA TERRA is a natural ligand and direct inhibitor of human telomerase. Nucleic Acids Res. 38, 5797-5806.

70. RL Flynn, RC Centore, RJ O'Sullivan, $R$ Rai, A Tse, Z Songyang, S Chang, J Karlseder, L Zou, TERRA and hnRNPAl orchestrate an RPA-toPOT1 switch on telomeric single-stranded DNA. Nature. 471, 532-536.

71. Samani N J, Boultby R, Butler R, Thompson JR \& Goodall AH (2001): Telomere shortening in atherosclerosis. Lancet. 358, 472-473.

72. Samper E, Flores JM \& Blasco MA (2001): Restoration of telomerase activity rescues chromosomal instability and premature aging in Terc-/- mice with short telomeres. EMBO Rep. 2, 1-8.

73. Sfeir A, Kosiyatrakul ST, HockemeyerD, MacRae S L, Karlseder J, Schildkraut C L and de Lange T (2009): Mammalian telomeres resemble fragile sites and require TRF1 for efficient replication. Cell. 138, 90-103.

74. Shay JW \& Wright WE (2002): Telomerase: a target for cancer therapeutics. Cancer Cell. 2, 257-265.

75. Stansel RM, de Lange T and Griffith JD (2001): T-loop assembly in vitro involves binding of TRF2 near the 39 telomeric overhang. EMBO J. 20, 5532-5540.

76. Stellwagen AE, Haimberger ZW, Veatch JR and Gottschling DE (2003): $\quad K u$ interacts with telomerase RNA to promote telomere addition at native and broken chromosome ends. Genes Dev. 17, 2384-2395.

77. TdeLange (2005): Shelterin:the protein complex that shapes and safe guards human telomeres. GenesDev. 19, 2100-2110.

78. Ting NS, Yu Y, Pohorelic B, Lees-Miller, SP and Beattie T L (2005): Human Ku70/80 interacts directly with $h T R$, the RNA component of human telomerase. Nucleic Acids Res. 33, 2090-2098.

79. Wang F, Podell E R, Zaug A J, Yang Y, Baciu P, Cech $T R$ and Lei $M$ (2007): The POT1-TPPI telomere complex is a telomerase processivity factor. Nature. 445, 506-510.

80. Watson JD \& Crick FH (1953): Molecular structure of nucleic acids; a structure for deoxyribose nucleic acid. Nature. 171, 737-738.

81. Wick M, Zubov D and Hagen G (1999): Genomic organization and promoter characterization of the gene encoding the human telomerase reverse transcriptase (hTERT). Gene. 232, 97-106.

82. Wiemann $S U$ et al. (2002): Hepatocyte telomere shortening and senescence are general markers of human liver cirrhosis. FASEB J. 16, 935-942.

83. Wyllie FS et al. (2000): Telomerase prevents the accelerated cell ageing of Werner syndrome fibroblasts. Nature Genet. 24, 16-17.

84. Xin H, Liu D, Wan M, Safari A, Kim H, Sun W, O'Connor M S and Songyang Z (2007): TPP1 is a homologue of ciliate TEBP-beta and interacts with POT1 to recruit telomerase. Nature. 445, 559-562.

85. Z Mao, A Seluanov, $Y$ Jiang, $V$ Gorbunova (2007): TRF2 is required for repair of nontelomeric DNA double-strand breaks by homo logous recombination. Proc Natl Acad Sci USA. 104, 13068-13073. 